\title{
Huperzine A ameliorates damage induced by acute myocardial infarction in rats through antioxidant, anti- apoptotic and anti-inflammatory mechanisms
}

\author{
XIZHONG SUI and CHANGQING GAO \\ Department of Cardiac Surgery, The PLA General Hospital, Medical School of Chinese PLA, Beijing 100098, P.R. China
}

Received July 26, 2013; Accepted October 21, 2013

DOI: $10.3892 /$ ijmm.2013.1546

\begin{abstract}
Huperzine A (HupA), an alkaloid used in traditional Chinese medicine and isolated from Huperzia serrata, has been shown to possess diverse biological activities. The present study was undertaken to evaluate the cardioprotective potential of HupA in myocardial ischemic damage using a rat model of acute myocardial infarction. HupA significantly diminished the infarct size and inhibited the activities of myocardial enzymes, including creatine kinase (CK), the MB isoenzyme of creatine kinase (CK-MB), lactate dehydrogenase (LDH) and cardiac troponin $\mathrm{T}$ (cTnT). A significantly reduced activity of malondialdehyde (MDA) and elevated activities of superoxide dismutase (SOD), of the non-enzymatic scavenger enzyme, glutathione (GSH), as well as of glutathione peroxidase (GSHPX) were found in the HupA-treated groups. Furthermore, decreased protein levels of caspase- 3 and Bax, and increased levels of $\mathrm{Bcl}-2$ were observed in the infarcted hearts of the rats treated with various concentrations of HupA. In addition, treatment with HupA markedly inhibited the expression of the nuclear factor- $\kappa \mathrm{B}(\mathrm{NF}-\kappa \mathrm{B})$ subunit $\mathrm{p} 65$, tumor necrosis factor- $\alpha$ $(\mathrm{TNF}-\alpha)$ and interleukin-1 $\beta$ (IL-1 $\beta$ ). These findings suggest that the cardioprotective potential of HupA is associated with its antioxidant, anti-apoptotic and anti-inflammatory properties in acute myocardial infarction in rats.
\end{abstract}

\section{Introduction}

Myocardial infarction is one of the most common ischemic heart diseases and a major cause of morbidity and mortality worldwide. It is a clinical syndrome arising from the sudden and persistent interruption of the myocardial blood supply,

Correspondence to: Dr Changqing Gao, Department of Cardiac Surgery, The PLA General Hospital, Medical School of Chinese PLA, 28 Fuxing Road, Beijing 100098, P.R. China

E-mail: changqinggao2012@163.com

Key words: huperzine A, acute myocardial infarction, cardioprotection, antioxidant, anti-apoptotic, anti-inflammatory eventually leading to the loss of cardiomyocytes. Although a number of drugs, including angiotensin-converting enzyme inhibitors, calcium channel blockers and angiotensin II receptor antagonists, has been widely used to treat myocardial ischemia in western medicine, the usefulness of these drugs has been limited due to their serious adverse effects, such as cardiac depression or even, proarrhythmic effects (1). There is great interest in the development of new types of cardioprotective drugs, which may attenuate the effects of myocardial infarction in clinical practice.

Cumulative evidence has demonstrated that cell death in myocardial infarction is mainly mediated by reactive oxygen species (ROS). A previous study demonstrated that the accumulation of oxygen free radicals following ischemia not only destroyed cellular structures, but further caused mitochondrial dysfunction, activating apoptotic signaling cascades (2). The fatty acids are attacked by an excess of free radicals in myocardial membranes. This causes a chain reaction of lipid peroxidation, which has a harmful effect on the myocardium during acute myocardial infarction (3). In addition, oxidative stress is intimately involved in the occurrence of myocardial ischemia. Therefore, the reduction of ROS may attenuate the effects of acute myocardial infarction.

Apoptosis has been shown to participate in the pathogenesis of myocardial injuries during myocardial infarction. Caspase-3 serves as an 'apoptotic effector' in response to apoptotic stimuli (4). It has previously been reported that a dramatic elevation of caspase-3 can cause damage in isoproterenol-induced Wistar rats with acute myocardial infarction (5). In addition, proteins of the $\mathrm{Bcl}-2$ family have been shown to play a central role in the regulation of cellular apoptosis. Bcl-2 is a cytosolic protein and serves as an anti-apoptotic molecule, whereas another member of the family, Bax, functions as a pro-apoptotic protein (6). These findings suggest that the regulation of caspase- $3, \mathrm{Bcl}-2$ and Bax proteins may attenuate the cardiac damage occuring in myocardial infarction.

Nuclear factor $-\kappa \mathrm{B}(\mathrm{NF}-\kappa \mathrm{B})$, which is found among most eukaryotes, is the hub of the related signal transduction pathway and is present in myocytes. Its levels can reflect the pathological changes occuring during acute myocardial infarction $(7,8)$. The activation of $N F-\kappa B$ can lead to the release of pro-inflammatory cytokines, such as tumor necrosis factor- $\alpha$ (TNF- $\alpha$ ) and interleukin-1 $\beta$ (IL-1 $\beta$ ). During myocardial infarc- 
tion, high levels of NF- $\mathrm{KB}$ p65, TNF- $\alpha$ and IL-1 $\beta$ in cells can promote myocardial necrosis and cellular apoptosis, eventually leading to serious heart failure. Thus, drugs that suppress the NF- $\mathrm{KB}$ signaling pathway and the release of pro-inflammatory factors may be used for the treatment of diverse cardiac disorders.

Huperzine A (HupA) is a compound found in the plant Qian Ceng Ta (Huperzia serrata), used in traditional Chinese medicine (9). It has been previously demonstrated to upregulate the cholinergic anti-inflammatory pathway and to inhibit immunosenescence and age-related disorders, such as Alzheimer's disease, by suppressing acetylcholinesterase (AChE) activity (10-13). Additionally, HupA has been reported to reduce oxidative damage in D-galactose-treated rats (14). However, it has not been well established whether HupA can protect against acute myocardial infarction in rats. Based on the above data, we hypothesized that HupA exerts cardioprotective effects in rats with acute myocardial infarction, and further explored the potential cardioprotective mechanisms involved.

\section{Materials and methods}

Ethics statement. The experimental protocols for animal handling were approved by the Animal Ethics Committee of the Medical School of Chinese PLA, Beijing, China.

Animals and induction of acute myocardial infarction. We purchased adult male Wistar rats (250-300 g) from the Beijing Animal Center (Beijing, China). The rats were housed in polypropylene cages under a controlled environment $(12: 12 \mathrm{~h}$ light/dark cycle, $50-70 \%$ humidity, $24^{\circ} \mathrm{C}$ ) with free access to water and food. The rat model of acute myocardial infarction was established as previously described with minor modifications (15). Briefly, the animals were anesthetized intraperitoneally (i.p.) with sodium pentobarbital $(40 \mathrm{mg} / \mathrm{kg}$ ). They were then intubated and artificially ventilated with a respirator. The standard electrocardiogram (II) was procured by a transducer attached to a multi-channel recorder $(\mathrm{BL}-420 \mathrm{~F}$; Chengdu Tai Meng Science and Technology Co. Ltd.,Chengdu, China), with electrodes subcutaneously inserted into the limbs of the animals. A 5-0 silk suture of 1-2 mm was selected to encircle the left anterior descending coronary artery under the left atrial appendage. The sham-operated animals underwent identical surgical procedures with the exception of the coronary artery ligation. Efforts were made to minimize the number of animals used and their suffering. Successful ligation was confirmed by an ST-segment elevation and regional cyanosis of the myocardial surface.

Drug administration. HupA (98\% pure; Sigma-Aldrich, St. Louis, MO, USA) was dissolved in physiological saline solution. The rats were randomly divided into 4 groups, 2 referred to as contorl and 2 as treated: i) the control sham-operated group, in which the rats were injected with physiological saline $(0.1 \mathrm{ml} / 100 \mathrm{~g}$, i.p.) and underwent identical surgery with the exception of the coronary artery ligation; ii) the control vehicle-treated group, in which the rats were injected with physiological saline $(0.1 \mathrm{ml} / 100 \mathrm{~g}$, i.p. $)$ and underwent the ligation of the left coronary artery; and iii) 2 HupA treatment groups, which were subjected to the ligation of the left coronary artery and treated with 167 and $500 \mu \mathrm{g} / \mathrm{kg}$ HupA, respectively. The rats were injected with physiological saline solution or HupA 7 consecutive days. Thirty minutes after the final injection, the rats underwent left coronary artery ligation.

Measurement of infarct size. The hearts were rapidly excised and the left ventricles were sliced into 2 -mm thick sections from the apex to the atrioventricular groove $6 \mathrm{~h}$ after the coronary artery was ligated, followed by incubation with $1 \%$ triphenyltetrazolium chloride (TTC) (Sigma-Aldrich) solution at $3^{\circ} \mathrm{C}$ for $30 \mathrm{~min}$. The normal myocardium was stained brick red, while the area without color corresponded to the ischemic heart muscle. The volume and weight of the rat hearts as a percentage of the left ventricle were used to calculate the size of the infarcted area.

Quantification of activities of cardiac marker enzymes. Six hours after the ligation of the coronary artery, the blood samples were collected in order to determine the activities of the myocardial-specific enzymes, creatine kinase (CK), the MB isoenzyme of creatine kinase (CK-MB), lactate dehydrogenase (LDH) and cardiac troponin $\mathrm{T}$ (cTnT). The colorimetric method was employed to determine the activities of CK, CK-MB and LDH following the manufacturer's instructions (Nanjing Jiancheng Bioengineering Institute, Nanjing, China). Serum cTnT levels were measured using the Elecsys 2010 immunoassay (Roche Diagnostics GmbH, Mannheim, Germany).

Measurement of malondialdehyde (MDA), superoxide dismutase (SOD), glutathione (GSH) and glutathione peroxidase (GSH-PX) activities. The enzymatic activities of MDA, SOD, GSH and GSH-PX in the heart homogenates were measured according to the instructions provided with the relevant commercially-available assay kits (Nanjing Jiancheng Bioengineering Institute). The concentration of MDA, a presumptive marker of oxidant-mediated lipid peroxidation, was quantified using the thiobarbituric acid (TBA)-reacting substances assay, followed by measuring the absorbance at a wavelength of $532 \mathrm{~nm}$. SOD activity was measured in the heart homogenates by calculating the rate of inhibition of nucleotide oxidation. The activities of GSH-PX and GSH were determined by quantifying the rate of oxidation of the reduced glutathione to the oxidized glutathione by $\mathrm{H}_{2} \mathrm{O}_{2}$. One unit of GSH-PX was represented as the quantity that reduced the level of GSH by $1 \mu \mathrm{M}$ in $1 \mathrm{~min} / \mathrm{mg}$ protein. Quantification of protein concentrations in the heart homogenates was performed using the Coomassie Brilliant Blue method and bovine serum albumin as the standard.

Caspase-3 activity assay. The cleavage of the chromogenic caspase substrate, acetyl-Asp-Glu-Val-Asp-p-nitroanilide (Ac-DEVD- $p \mathrm{NA}$ ), by caspase- 3 was used to measure the activity of the enzyme. The amount of caspase- 3 was measured by the colorimetric approach using a commercial kit (Beyotime Institute of Biotechnology, Beijing, China). The protein samples from the heart muscles were acquired as described below in 'Western blot analysis'. Approximately $50 \mu \mathrm{g}$ of protein was added to the reaction buffer containing Ac-DEVD- $p$ NA $(2 \mathrm{mM})$, incubated at $37^{\circ} \mathrm{C}$ for $4 \mathrm{~h}$, and the absorbance of yellow $p$ NA was calculated by a spectrometer at a wavelength 
of $405 \mathrm{~nm}$. The activity of caspase-3, normalized as to the total protein activity in heart muscle, was then expressed as a fold change, compared with the baseline caspase- 3 activity of the control (sham-operated) group.

Western blot analysis. Western blot analysis was performed on the heart samples from each group. Briefly, heart muscle from different samples was homogenized in ice-cold RIPA buffer. Following centrifugation at $13,200 \times \mathrm{g}$ for $20 \mathrm{~min}$ at $4^{\circ} \mathrm{C}$, the supernatant was collected and the total protein level was measured using a standard BCA method (Beyotime Institute of Biotechnology).

Proteins $(50 \mu \mathrm{g})$ were separated in 8 or $10 \%$ SDS-polyacrylamide gels and transferred onto nitrocellulose membranes (Millipore, Billerica, MA, USA). The membranes were blocked with $5 \%$ fat-free milk for $2 \mathrm{~h}$ at room temperature and then incubated with a primary antibody overnight at $4^{\circ} \mathrm{C}$. The primary antibodies used were as follows: rabbit anti-caspase-3 (1:300), rabbit anti-Bcl-2 (1:200), rabbit anti-Bax (1:200) (all from Santa Cruz Biotechnology, Inc., Santa Cruz, CA, USA) and mouse anti-GAPDH (1:2,000; Kang Chen, Shanghai, China). The membranes were then rinsed and incubated with horseradish peroxidase-conjugated goat anti-rabbit antibody $(1: 5,000)$ or goat anti-mouse antibody $(1: 5,000)$ (both from Santa Cruz Biotechnology, Inc.) for $2 \mathrm{~h}$. The detection of immunolabeled protein bands was performed using an enhanced chemiluminescence (ECL) kit (Pierce, Rockford, IL, USA), followed by exposure to an X-ray film. GAPDH was used as the loading control. The quantification of protein band intensities was carried out using Quantity One software (Bio-Rad, Hercules, CA, USA).

Measurement of $N F-\kappa B, T N F-\alpha$ and $I L-1 \beta$ levels. The nuclear levels of p65 may positively correlate with the activation of the NF- $\kappa$ B pathway. The NF- $\kappa$ B/p65 ActivELISA kit (Imgenex, San Diego, CA, USA) was used to measure the levels of NF- $\kappa \mathrm{B}$-free p65 in the nuclear lysates following the manufacturer's instructions. The quantification of TNF- $\alpha$ and IL- $\beta$ was carried out using the TNF- $\alpha$ and IL-1 $\beta$ Quantikine Rat immunoassay kits following the manufacturer's instructions (R\&D Systems, Minneapolis, MN, USA).

Statistical analysis. Data are expressed as the means \pm SD from 6 rats in each group. Experimental results were analyzed using a one-way ANOVA followed by Dunnett's test for individual comparisons between the means of each group. All statistical analyses were performed using SPSS 13.0 software. A value of $\mathrm{P}<0.05$ was considered to indicate a statistically significant difference.

\section{Results}

Effects of HupA on myocardial infarct size in a rat model of acute myocardial infarction. The chemical structure of HupA is illustrated in Fig. 1. The infarct size in the vehicle-treated group was $39.31 \pm 2.78 \%$. Following treatment with HupA at concentrations of 167 and $500 \mu \mathrm{g} / \mathrm{kg}$, the size of the infarcted area significantly decreased to $31.77 \pm 1.74 \%(\mathrm{P}<0.01)$ and $26.21 \pm 1.91 \%(\mathrm{P}<0.01)$, respectively, in comparison with the vehicle-treated group (Fig. 2).

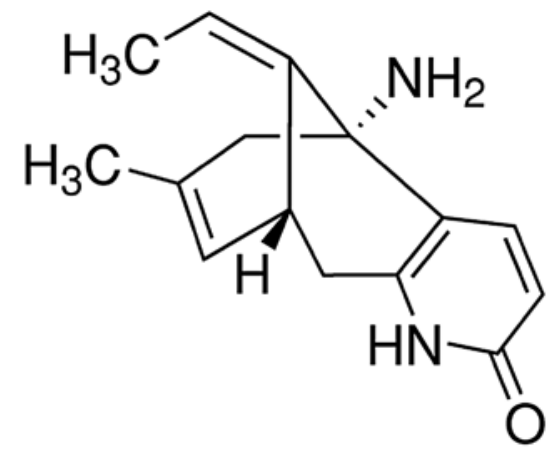

Figure 1. Chemical structure of huperzine A.

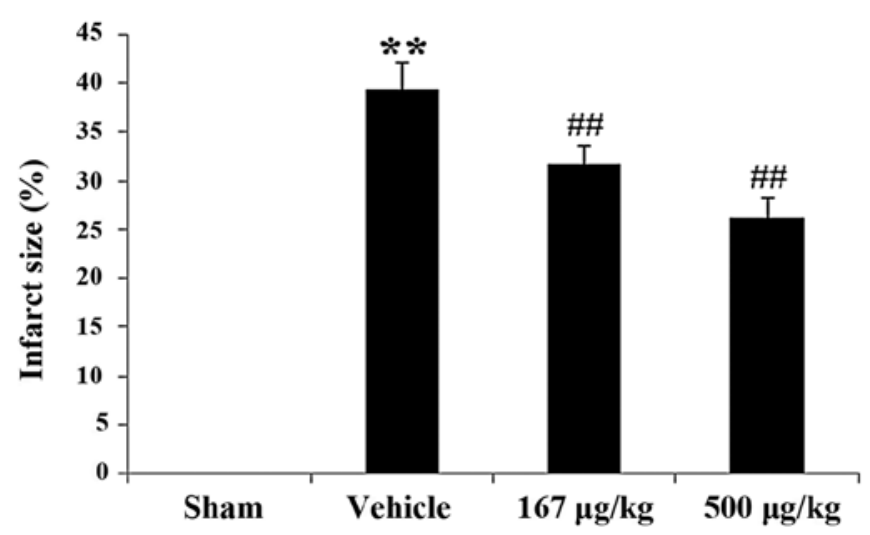

Figure 2.Effects of huperzine A (HupA) on infarct size of hearts of rats subjected to acute myocardial infarction (means $\pm \mathrm{SD}, \mathrm{n}=6$ ). ${ }^{\# \#} \mathrm{P}<0.01$ vs. vehicletreated group. Sham, sham-operated; vehicle, vehicle-treated; $167 \mu \mathrm{g} / \mathrm{kg}$, HupA $(167 \mu \mathrm{g} / \mathrm{kg})$-treated; $500 \mu \mathrm{g} / \mathrm{kg}$, HupA (500 $\mu \mathrm{g} / \mathrm{kg})$-treated.

Effects of HupA on serum CK, CK-MB, LDH and cTnT levels in a rat model of acute myocardial infarction. The measurements of serum CK, CK-MB, LDH and cTnT levels in the control and treated groups are summarized in Table I. The rats with acute myocardial infarction showed a significant increase in serum levels of CK, CK-MB, LDH and cTnT $(\mathrm{P}<0.01)$ as compared with the sham-operated control group. Pre-treatment with 167 and $500 \mu \mathrm{g} / \mathrm{kg}$ HupA significantly decreased $(\mathrm{P}<0.01)$ the serum levels of CK, CK-MB, LDH and cTnT in the rats subjected to myocardial infarction vs. the vehicle-treated group.

Effects of HupA on the activities of MDA, SOD, GSH-PX and $G S H$ in a rat model of acute myocardial infarction. Table II demonstrates the activities of MDA, SOD, GSH-PX and GSH in the rat hearts from the control and treated groups. Rats subjected to acute myocardial infarction exhibited a marked increase in MDA levels, an indicator of lipid peroxidation, as compared with the sham-operated control rats $(\mathrm{P}<0.01)$. The administration of 167 and $500 \mu \mathrm{g} / \mathrm{kg}$ HupA to the rats with myocardial infarction significantly reduced ischemia-mediated lipid peroxidation in comparison with the vehicle-treated group ( $\mathrm{P}<0.01$ for both HupA concentrations). Furthermore, the activities of antioxidants and antioxidative enzymes were measured in the heart homogenates from the control and treated groups. Rats with acute myocardial infarction showed 
Table I. Effects of HupA on serum levels of CK, CK-MB, LDH and cTnT in rats subjected to acute myocardial infarction.

\begin{tabular}{lcrrr}
\hline Group & CK & CK-MB & \multicolumn{1}{c}{ LDH } & \multicolumn{1}{c}{ cTnT } \\
\hline Sham-operated group & $0.24 \pm 0.05$ & $78.08 \pm 2.61$ & $1838 \pm 405.69$ & $0.058 \pm 0.03$ \\
Vehicle-treated group & $0.58 \pm 0.07^{\mathrm{a}}$ & $186.16 \pm 6.11^{\mathrm{a}}$ & $3748.5 \pm 398.27^{\mathrm{a}}$ & $0.3 \pm 0.05^{\mathrm{a}}$ \\
HupA $(167 \mu \mathrm{g} / \mathrm{kg})$ & $0.41 \pm 0.06^{\mathrm{b}}$ & $115.87 \pm 7.29^{\mathrm{b}}$ & $3165.67 \pm 405.44^{\mathrm{b}}$ & $0.19 \pm 0.05^{\mathrm{b}}$ \\
HupA $(500 \mu \mathrm{g} / \mathrm{kg})$ & $0.29 \pm 0.08^{\mathrm{b}}$ & $93.45 \pm 7.42^{\mathrm{b}}$ & $2455.5 \pm 319.19^{\mathrm{b}}$ & $0.17 \pm 0.04^{\mathrm{b}}$ \\
\hline
\end{tabular}

${ }^{\text {ap }}<0.01$ vs. sham-operated group; ${ }^{b} \mathrm{P}<0.01$ vs. vehicle-treated group. HupA, huperzine $\mathrm{A} ; \mathrm{CK}$, creatine kinase; CK-MB, MB isoenzyme of creatine kinase; $\mathrm{LDH}$, lactate dehydrogenase; cTnT, cardiac troponin T. Data are presented as the means $\pm \mathrm{SD}(\mathrm{n}=6)$.

Table II. Effects of HupA on MDA, SOD, GSH-PX and GSH activities in the hearts of rats subjected to acute myocardial infarction.

\begin{tabular}{lllll}
\hline Group & MDA & SOD & GSH-PX & GSH \\
\hline Sham-operated group & $25.19 \pm 1.07$ & $6.29 \pm 0.73$ & $6.29 \pm 0.73$ & $34.81 \pm 2.69$ \\
Vehicle-treated group & $16.29 \pm 0.80^{\mathrm{a}}$ & $3.34 \pm 0.18^{\mathrm{a}}$ & $3.34 \pm 0.18^{\mathrm{a}}$ & $23.61 \pm 2.15^{\mathrm{a}}$ \\
HupA $(167 \mu \mathrm{g} / \mathrm{kg})$ & $20.90 \pm 1.00^{\mathrm{b}}$ & $4.87 \pm 0.48^{\mathrm{b}}$ & $4.87 \pm 0.48^{\mathrm{b}}$ & $28.85 \pm 1.79^{\mathrm{b}}$ \\
HupA $(500 \mu \mathrm{g} / \mathrm{kg})$ & $22.22 \pm 1.24^{\mathrm{b}}$ & $5.25 \pm 0.25^{\mathrm{b}}$ & $5.25 \pm 0.25^{\mathrm{b}}$ & $30.54 \pm 2.21^{\mathrm{b}}$ \\
\hline
\end{tabular}

${ }^{\mathrm{a}} \mathrm{P}<0.01$ vs. sham-operated group; ${ }^{\mathrm{b}} \mathrm{P}<0.01$ vs. vehicle-treated group. HupA, huperzine A; MDA, malondialdehyde; SOD, superoxide dismutase; GSH-PX, glutathione peroxidase; GSH, glutathione. Data are presented as the means \pm SD $(n=6)$.

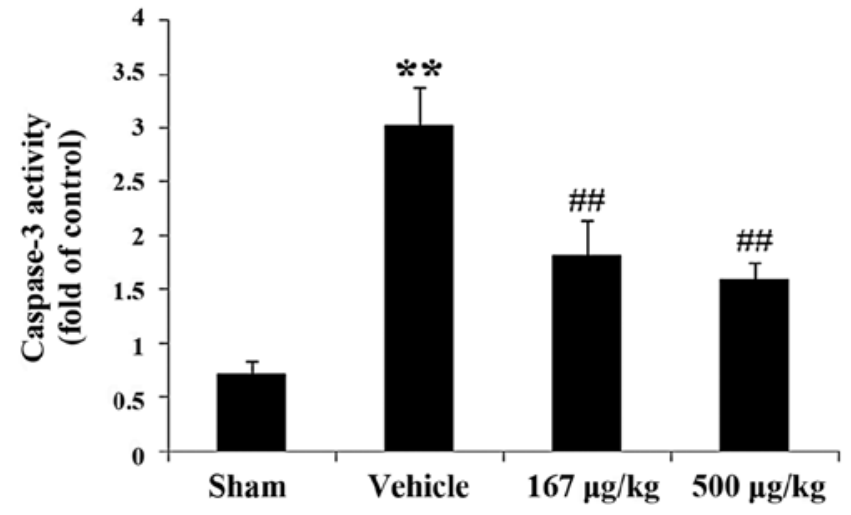

Figure 3. Effects of huperzine A (HupA) on caspase-3 activity in the hearts of rats in the control group and group subjected to acute myocardial infarction (means $\pm \mathrm{SD}, \mathrm{n}=6$ ). ${ }^{* *} \mathrm{P}<0.01$ vs. sham-operated group; ${ }^{\# \#} \mathrm{P}<0.01$ vs. vehicletreated group. Sham, sham-operated; vehicle, vehicle-treated; $167 \mu \mathrm{g} / \mathrm{kg}$, HupA $(167 \mu \mathrm{g} / \mathrm{kg})$-treated; $500 \mu \mathrm{g} / \mathrm{kg}$, HupA (500 $\mu \mathrm{g} / \mathrm{kg})$-treated groups.

a significant reduction in SOD, GSH-PX and GSH activities $(\mathrm{P}<0.01)$ vs. the control rats. However, following treatment with HupA (167 or $500 \mu \mathrm{g} / \mathrm{kg})$, a significant elevation in the activities of SOD, GSH-PX and GSH was observed in the infarcted rat heart as compared with the vehicle-treated group $(\mathrm{P}<0.01$ for both HupA concentrations).

Effects of HupA on caspase-3 activity in a rat model of acute myocardial infarction. In order to explore whether HupA attenuates the apoptotic damage induced by myocardial infarction, the activity of caspase- 3 , an effector of the apoptotic signaling pathway, was determined by colorimetric analysis. Caspase- 3 activity was markedly elevated by $319.92 \%(\mathrm{P}<0.01)$ in the vehicle-treated group as compared with the sham-operated group (Fig. 3). In the HupA-treated (167 and $500 \mu \mathrm{g} / \mathrm{kg}$ ) groups, there was a significant reduction in caspase-3 activity by $39.80 \%(\mathrm{P}<0.01)$ and $47.03 \%(\mathrm{P}<0.01)$, respectively, as compared with the vehicle-treated group.

Effects of HupA on the protein expression of caspase-3, Bcl-2 and Bax in a rat model of acute myocardial infarction. To corroborate the fact that HupA prevents cardiac damage induced by acute myocardial infarction in rats, western blot analysis was carried out to determine the expression levels of the apoptosis-related proteins, caspase-3, Bcl-2 and Bax, in the rat hearts. Western blot analysis with caspase-3 antibody exhibited a specific band of $20 \mathrm{kDa}$, characteristic of caspase-3 (Fig. 4A). The protein expression of caspase- 3 in the vehicle-treated group with myocardial infarction was markedly increased in the rat hearts as compared with the sham-operated control group $(\mathrm{P}<0.01)$. Nevertheless, upon treatment with HupA (167 or $500 \mu \mathrm{g} / \mathrm{kg})$ a marked reduction in caspase-3 protein expression was observed in the infarcted rats $(\mathrm{P}<0.01$ for both HupA concentrations) in comparison to the vehicle-treated group (Fig. 4B). Thus, these results further confirmed that HupA treatment reduced the caspase- 3 protein level in a rat model of acute myocardial infarction, in line with the caspase- 3 activity measurements. In addition, proteins of the Bcl-2 family, such as Bcl-2 and Bax, are considered to play a pivotal role in the regulation of apoptotic cascades. Fig. 4A shows that these proteins were detected in bands of $26 \mathrm{kDa}$ for $\mathrm{Bcl}-2$ and $23 \mathrm{kDa}$ for Bax. The statistical comparison revealed a statistically significant reduction in Bcl-2 and a marked elevation in Bax protein levels in the vehicle-treated rats $(\mathrm{P}<0.01)$ as compared with the sham-operated group. However, upon treatment with HupA (167 or $500 \mu \mathrm{g} / \mathrm{kg}$ ), 
Table III. Effects of HupA on NF- $\mathrm{B}$ p65, TNF- $\alpha$ and IL-1 $\beta$ levels in the hearts of rats subjected to acute myocardial infarction.

\begin{tabular}{llcr}
\hline Group & NF- $\kappa$ B p65 & TNF- $\alpha$ & IL-1 $\beta$ \\
\hline Sham-operated group & $13.17 \pm 1.12$ & $84.47 \pm 2.33$ & $2.16 \pm 0.13$ \\
Vehicle-treated group & $45.32 \pm 1.02^{\mathrm{a}}$ & $410.92 \pm 8.56^{\mathrm{a}}$ & $6.25 \pm 0.27^{\mathrm{a}}$ \\
HupA $(167 \mu \mathrm{g} / \mathrm{kg})$ & $35.17 \pm 0.71^{\mathrm{b}}$ & $377.76 \pm 15.74^{\mathrm{b}}$ & $4.20 \pm 0.23^{\mathrm{b}}$ \\
HupA $(500 \mu \mathrm{g} / \mathrm{kg})$ & $25.98 \pm 0.88^{\mathrm{b}}$ & $254.73 \pm 7.29^{\mathrm{b}}$ & $3.54 \pm 0.26^{\mathrm{b}}$
\end{tabular}

${ }^{\mathrm{a}} \mathrm{P}<0.01$ vs. sham-operated group; ${ }^{\mathrm{b}} \mathrm{P}<0.01$ vs. vehicle-treated group. HupA, huperzine $\mathrm{A}$; $\mathrm{NF}-\kappa \mathrm{B}$, nuclear factor- $\kappa \mathrm{B}$; TNF- $\alpha$, tumor necrosis factor- $\alpha$; IL-1 $\beta$, interleukin- $1 \beta$. Data are presented as the means \pm SD $(n=6)$.
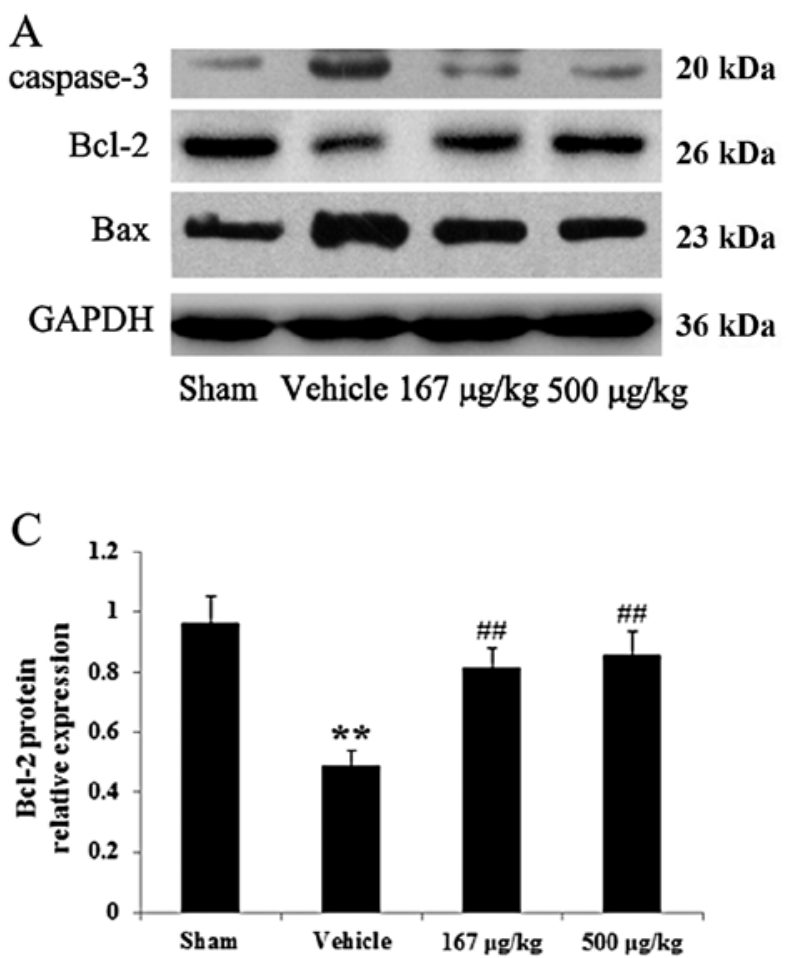
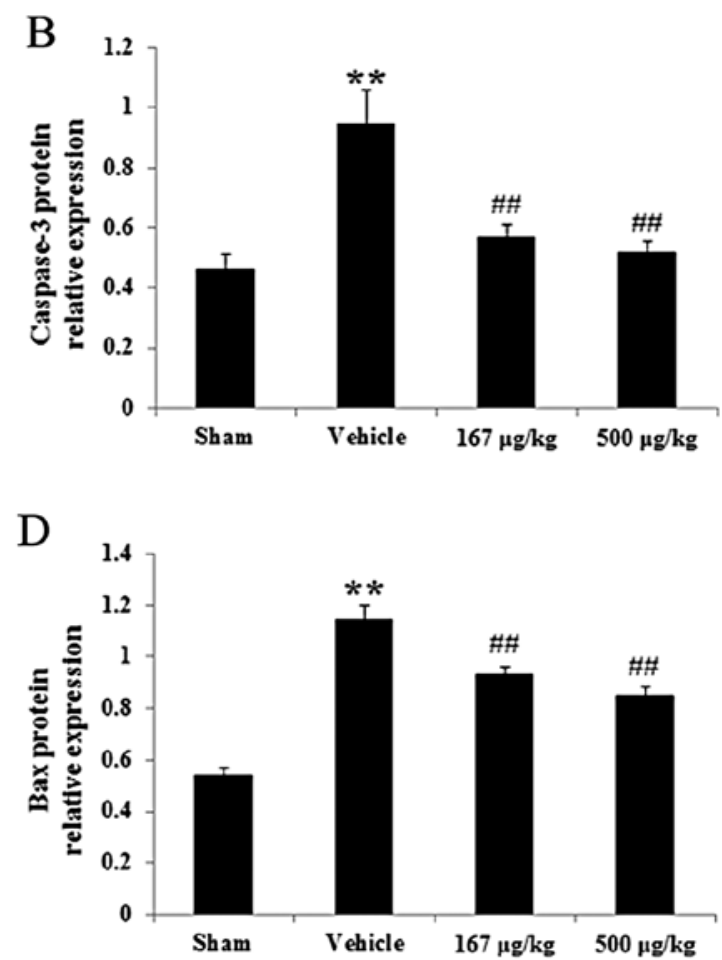

Figure 4. Effects of huperzine A (HupA) on the protein expression of caspase-3, Bcl-2 and Bax in the hearts of rats in the control group and group subjected to acute myocardial infarction (means $\pm \mathrm{SD}, \mathrm{n}=6$ ). (A) Representative images of immunoblots with antibodies against caspase-3, Bcl-2 and Bax in the hearts of rats from the different groups. Caspase-3, $20 \mathrm{kDa}$; Bcl-2, $26 \mathrm{kDa}$; Bax, $23 \mathrm{kDa}$; GAPDH, $36 \mathrm{kDa}$. (B-D) Quantitative analysis of the protein levels of caspase-3, Bcl-2 and $\mathrm{Bax}$ in the hearts of rats from the different groups. The data were normalized to the loading control GAPDH. ${ }^{* *} \mathrm{P}<0.01 \mathrm{vs}$. sham-operated group; ${ }^{\# \#} \mathrm{P}<0.01$ vs. vehicle-treated group. Sham, sham-operated; vehicle, vehicle-treated; $167 \mu \mathrm{g} / \mathrm{kg}$, HupA (167 $\mu \mathrm{g} / \mathrm{kg})$-treated; $500 \mu \mathrm{g} / \mathrm{kg}, \mathrm{HupA}(500 \mu \mathrm{g} / \mathrm{kg})$-treated.

we observed strikingly elevated and markedly decreased levels of Bcl-2 and Bax, respectively ( $\mathrm{P}<0.01$ for both HupA concentrations) in the infarcted rat hearts as compared with the vehicle-treated group (Fig. 4C and D).

Effects of HupA on protein expression of NF- $\kappa B$ p 65, TNF- $\alpha$ and $I L-1 \beta$ in a rat model of acute myocardial infarction. Table III shows the effects of HupA on the protein levels of the inflammatory response molecules, NF- $\mathrm{kB}$ p65, TNF- $\alpha$ and IL-1 $\beta$, in a rat model of acute myocardial infarction. It was found that the levels of NF- $\kappa$ B p65 $(\mathrm{P}<0.01)$, TNF- $\alpha(\mathrm{P}<0.01)$ and IL-1 $\beta(\mathrm{P}<0.01)$ were markedly increased in the vehicletreated group with myocardial infarction. However, treatment with HupA (167 or $500 \mu \mathrm{g} / \mathrm{kg}$ ) induced a reduction in $\mathrm{NF}-\kappa \mathrm{B}$ p65 $(\mathrm{P}<0.01)$, TNF- $\alpha(\mathrm{P}<0.01)$ and IL-1 $\beta(\mathrm{P}<0.01)$ levels in comparison to the group subjected to myocardial infarction.

\section{Discussion}

To our knowledge, the results of the present study revealed for the first time that: i) HupA has the potential to decrease the myocardial infarct size and the activities of CK, CK-MB, LDH in serum, as well as those of cTnT in a rat model of acute myocardial infarction; ii) HupA markedly inhibited lipid peroxidation (MDA production), but increased the activities of endogenous antioxidant enzymes (SOD and GSH), as well as those of the non-enzymatic scavenger, GSH-PX, in a rat model of acute myocardial infarction; iii) HupA treatment of rats with myocardial infarction resulted in a marked decrease in caspase- 3 and Bax levels, and in an elevated Bcl-2 expression at the protein level; iv) HupA inhibited the protein expression of the major inflammatory factors, NF- $\kappa \mathrm{B}$ p65, TNF- $\alpha$ and IL-1 $\beta$, in the infarcted rat hearts. These findings support the 
hypothesis that the cardioprotective effects induced by HupA are associated with its antioxidant, anti-apoptotic and antiinflammatory properties.

HupA, which is isolated from numerous plants of the Lamiaceae family, is a major phenolic monoterpene and has various pharmacological actions. It has been widely used in the food industry and clinical dentistry. The present study extended the spectrum of the therapeutic effects of HupA and demonstrated its potential as a potent cardioprotective agent in a rat model of acute myocardial infarction.

In ischemic heart disease, the infarct size and the activities of myocardial-specific enzymes, such as CK, CK-MB, LDH and cTnT, are known as important parameters for evaluating cardiac injury. Previous studies have demonstrated a prominent elevation of infarct size and of the activities of myocardial-specific enzymes, including CK, CK-MB and LDH, in rats with acute myocardial infarction $(5,16)$. The activity of serum cTnT is a very specific and sensitive indicator of myocardial infarction. cTnT is a contractile protein that is rarely found in serum but is abundantly released when myocardial necrosis occurs (17). Consistent with previous reports, the present study illustrated that the infarct size and the activities of CK, CK-MB, LDH and cTnT significantly increased in rats subjected to myocardial infarction. Moreover, the activities of these enzymes were significantly reduced following treatment with HupA, demonstrating the cardioprotective effects of HupA.

It is well established that the excessive generation of oxygen free radicals is a pivotal factor that exacerbates cellular damage during ischemic attack. Under normal conditions, the generation of oxygen free radicals is kept under homeostatic control by endogenous antioxidant enzymes, such as SOD and GSH-PX, and by low-molecular weight antioxidants. The first line of cellular defense against oxidative injury may be the anti-oxidative system. A number of drugs based on antioxidants and radical scavengers has been shown to contribute to a favorable outcome in the therapy of ischemic diseases $(18,19)$. Furthermore, the liberation of lipid aldehydes and peroxides is facilitated by cellular membrane damage. MDA is synthesized during the oxidation of fatty acids within myocardial membranes and causes a ripple effect of lipid peroxidation. Therefore, MDA may serve as an indicator of structural oxidative injury of cell membranes. The present study demonstrated that HupA induced a significant reduction in MDA, as well as in SOD, GSH and GSH-PX activities in the infarcted rat hearts. This result indicated that the cardioprotective effects of HupA against acute myocardial infarction are associated with its antioxidant properties.

The cardiac impairment of ischemic patients occurs via oxidative stress and could lead to mitochondrial dysfunction and hence, activate an apoptotic cascade. To further explore the protective effects of HupA against cardiac injury induced by acute myocardial infarction in rats, we measured the levels of apoptosis-related proteins in the rat hearts. Caspases are evolutionarily conserved cysteinyl proteases with a central role in the apoptotic signaling pathway; among them, caspase- 3 is a critical molecule in the caspase-dependent apoptotic cascade. Caspase- 3 has previously been reported to activate a variety of substrates that presumably cause DNA fragmentation and cell death (20). An increasing number of studies has revealed the upregulation of caspase- 3 following acute myocardial infarction $(5,15)$. The present study demonstrated that treatment with HupA markedly reduced caspase-3 activity in the infarcted rat hearts. In agreement with our findings, Wang and Tang (9) also reported that HupA significantly decreased the expression level of caspase-3 in Alzheimer's disease. In addition to caspases, proteins of the Bcl-2 family have been shown to be involved in the modulation of ischemia-induced apoptosis in rat myocytes. Bcl-2 itself acts as a repressor of apoptosis, while another member of the family, Bax, functions as a promoter of cell death (6). It has previously been reported that myocardial infarction induces a marked reduction in the expression of the anti-apoptotic protein, Bcl-2, and an increase in the expression of the apoptotic-promoting molecule, Bax $(21,22)$. In agreement with previous studies, our findings demonstrated a significant downregulation of Bcl-2 and an upregulation of Bax in rats subjected to acute myocardial infarction. However, the alterations in the levels of Bcl-2 and Bax caused by ischemic damage were prevented by the administration of HupA. In addition, our results demonstrated a reduction in caspase- 3 activity in the rats subjected to myocardial infarction treated with HupA, suggesting that the cadioprotective effects of HupA are associated with its anti-apoptotic properties in acute myocardial infarction in rats.

Previous studies have suggested that the inflammatory response participates in the pathogenesis of ischemic heart diseases, and $\mathrm{NF}-\kappa \mathrm{B}$ is regarded as an important factor in this respect $(23,24)$. The activation of $N F-\kappa B$ leads to the release of pro-inflammatory cytokines, such as TNF- $\alpha$ and IL-1 $\beta$. The inhibition of the NF- $\kappa \mathrm{B}$ pathway has previously been reported to improve adverse left ventricular remodeling and cardiac dysfunction following myocardial infarction (25). Our study revealed that HupA inhibited the excessive activation of NF- $\kappa$ B p65 and reduced the release of TNF- $\alpha$ and IL-1 $\beta$ in rats subjected to myocardial infarction. Consistently, Ruan et al (14) found that HupA exerted anti-inflammatory effects against D-galactose-treated rats. In addition, a previous study illustrated that HupA inhibited the nuclear translocation of $\mathrm{NF}-\kappa \mathrm{B}$ and decreased the expression of pro-inflammatory factors following transient focal cerebral ischemia (26). Taken together, these findings suggest that HupA exerts cardioprotective effects against acute myocardial infarction through anti-inflammatory mechanisms.

In conclusion, the present study demonstrates that HupA attenuates the damage induced by acute myocardial infarction. The cardioprotective effects of HupA may be associated with its antioxidan, anti-apoptotic and anti-inflammatory properties. To our knowledge, our study presents the first evidence of the potential cardioprotective profile and related mechanisms of action of HupA. Our results also support the hypothesis that HupA may be a promising cardioprotective agent for the treatment of acute myocardial infarction. However, more detailed studies are required to fully elucidate its effects and mechanisms of action.

\section{References}

1. Yang B, Lin H, Xiao J, et al: The muscle-specific microRNA miR-1 regulates cardiac arrhythmogenic potential by targeting GJA1 and KCNJ2. Nat Med 13: 486-491, 2007. 
2. Chan PH: Mitochondria and neuronal death/survival signaling pathways in cerebral ischemia. Neurochem Res 29: 1943-1949, 2004.

3. Priscilla DH and Prince PS: Cardioprotective effect of gallic acid on cardiac troponin-T, cardiac marker enzymes, lipid peroxidation products and antioxidants in experimentally induced myocardial infarction in Wistar rats. Chem Biol Interact 179: 118-124, 2009.

4. Tanaka M, Mokhtari GK, Terry RD, et al: Overexpression of human copper/zinc superoxide dismutase (SOD1) suppresses ischemia-reperfusion injury and subsequent development of graft coronary artery disease in murine cardiac grafts. Circulation 110: II200-II206, 2004.

5. Guo J, Li HZ, Wang LC, et al: Increased expression of calciumsensing receptors in atherosclerosis confers hypersensitivity to acute myocardial infarction in rats. Mol Cell Biochem 366 $345-354,2012$

6. Mao X, Ji C, Sun C, et al: Topiramate attenuates cerebral ischemia/reperfusion injury in gerbils via activating GABAergic signaling and inhibiting astrogliosis. Neurochem Int 60:39-46, 2012.

7. Muller DN, Mervaala EM, Dechend R, et al: Angiotensin II (AT(1)) receptor blockade reduces vascular tissue factor in angiotensin II-induced cardiac vasculopathy. Am J Pathol 157: 111-122, 2000.

8. Speir E: Cytomegalovirus gene regulation by reactive oxygen species. Agents in atherosclerosis. Ann NY Acad Sci 899: 363-374, 2000

9. Wang R and Tang XC: Neuroprotective effects of huperzine A. A natural cholinesterase inhibitor for the treatment of Alzheimer's disease. Neurosignals 14: 71-82, 2005.

10. Pollak Y, Gilboa A, Ben-Menachem O, Ben-Hur T, Soreq H and Yirmiya R: Acetylcholinesterase inhibitors reduce brain and blood interleukin-1 $\beta$ production. Ann Neurol 57: 741-745, 2005.

11. Tabet N: Acetylcholinesterase inhibitors for Alzheimer's disease: anti-inflammatories in acetylcholine clothing! Age Ageing 35: 336-338, 2006.

12. Nizri E, Hamra-Amitay Y, Sicsic C, Lavon I and Brenner T: Anti-inflammatory properties of cholinergic up-regulation: A new role for acetylcholinesterase inhibitors. Neuropharmacology 50: 540-547, 2006

13. Brenner T, Nizri E, Irony-Tur-Sinai M, Hamra-Amitay $\mathrm{Y}$ and Wirguin I: Acetylcholinesterase inhibitors and cholinergic modulation in Myasthenia Gravis and neuroinflammation. J Neuroimmunol 201-202: 121-127, 2008
14. Ruan Q, Liu F, Gao Z, et al: The anti-inflamm-aging and hepatoprotective effects of huperzine $\mathrm{A}$ in D-galactose-treated rats. Mech Ageing Dev 134: 89-97, 2013.

15. Hong-Li S, Lei L, Lei S, et al: Cardioprotective effects and underlying mechanisms of oxymatrine against ischemic myocardial injuries of rats. Phytother Res 22: 985-989, 2008.

16. Ming X, Tongshen W, Delin W and Ronghua Z: Cardioprotective effect of the compound yangshen granule in rat models with acute myocardial infarction. Evid Based Complement Alternat Med 2012: 717123, 2012.

17. Katus HA, Remppis A, Scheffold T, Diederich KW and Kuebler W: Intracellular compartmentation of cardiac troponin T and its release kinetics in patients with reperfused and nonreperfused myocardial infarction. Am J Cardiol 67: 1360-1367, 1991.

18. Yamada J, Yoshimura S, Yamakawa H, et al: Cell permeable ROS scavengers, Tiron and Tempol, rescue PC12 cell death caused by pyrogallol or hypoxia/reoxygenation. Neurosci Res 45: 1-8, 2003

19. Li Y, Bao Y, Jiang B, et al: Catalpol protects primary cultured astrocytes from in vitro ischemia-induced damage. Int $\mathbf{J}$ Dev Neurosci 26: 309-317, 2008.

20. Manabat C, Han BH, Wendland M, et al: Reperfusion differentially induces caspase-3 activation in ischemic core and penumbra after stroke in immature brain. Stroke 34: 207-213, 2003.

21. Liu X, Gu J, Fan Y, Shi H and Jiang M: Baicalin attenuates acute myocardial infarction of rats via mediating the mitogen-activated protein kinase pathway. Biol Pharm Bull 36: 988-994, 2013.

22. Yu W, Liu Q and Zhu S: Carvacrol protects against acute myocardial infarction of rats via anti-oxidative and anti-apoptotic pathways. Biol Pharm Bull 36: 579-584, 2013

23. Frantz S, Fraccarollo D, Wagner H, et al: Sustained activation of nuclear factor kappa B and activator protein 1 in chronic heart failure. Cardiovasc Res 57: 749-756, 2003.

24. Wong SC, Fukuchi M, Melnyk P, Rodger I and Giaid A: Induction of cyclooxygenase- 2 and activation of nuclear factor-kappaB in myocardium of patients with congestive heart failure. Circulation 98: 100-103, 1998

25. Yoshiyama M, Omura T, Takeuchi K, et al: Angiotensin blockade inhibits increased JNKs, AP-1 and NF-kappa B DNA-binding activities in myocardial infarcted rats. J Mol Cell Cardiol 33: 799-810, 2001

26. Wang ZF, Wang J, Zhang HY and Tang XC: Huperzine A exhibits anti-inflammatory and neuroprotective effects in a rat model of transient focal cerebral ischemia. J Neurochem 106: 1594-1603, 2008 . 